TP Periodica Polytechnica

Mechanical Engineering

59(1), pp. 16-22, 2015

DOI: $10.3311 /$ PPme. 7516

Creative Commons Attribution (i)

RESEARCH ARTICLE

\section{Experimental Model for the Main Cutting Force in Face Milling of a High Strength Structural Steel}

\author{
István Biró $^{1 *}$, Miklós Czampa ${ }^{1}$, Tibor Szalay ${ }^{1}$
}

Received 09 May 2014; accepted after revision 08 September 2014

\begin{abstract}
Machining and more specifically face milling are productive ways of material shaping. Predictive models are very important for effective: quick, easy-to-use and accurate process planning. There are many industrial and scientific researches about modelling the prominent process parameters of machining, notably the machining forces. The main cutting force is one of the most important indicators as it is a primary output parameter of the chip-removing process. The specific cutting force is long time used, traditional type of modelling the main cutting force but still there are missing or difficult-to-find numerical information about the effect of some of the input machining parameters such as cutting speed. In this research, the effects of the theoretical chip-section geometry and the cutting speed were examined through face milling experiments of the $S 960 Q L$ high strength structural steel.
\end{abstract}

\section{Keywords}

cutting speed, specific cutting force, main cutting force, face milling

${ }^{1}$ Department of Manufacturing Science and Engineering, Faculty of

Mechanical Engineering, Budapest University of Technology and Economics, H-1111 Budapest, Hungary

*Corresponding author, e-mail: biro@manuf.bme.hu

\section{Introduction}

Machining is one of the most effectively and most expansively used part shaping method. To describe a machining process, competent and accurate models are needed. Models are the scientific projections of a process in the real world: in terms of basic industrial and technical aspects parametrical and complex but still easy-to-use models are the best choice to create predictive process planning methods.

Machining forces are natural accompanies of the machining process: due to the material properties, the workpiece shows mechanical resistance against deformation and chipping. The resultant machining force can be modelled as a vector in a Descartes-type coordinate system which is fixed to the working edge of the tool. According to this interpretation, the resultant force has three vectorial components (see Fig. 1 where $n$ is the rotating direction of the workpiece in turning and of the tool in milling and drilling, $\mathrm{v}_{\mathrm{f}}$ is the tool's feeding movement):

- $\mathrm{F}_{\mathrm{c}}$ - the main cutting force: a consequence of the main movement of the tool, thus being primarily responsible for the chipping process;

- $\mathrm{F}_{\mathrm{f}}$ - the feeding force: a consequence of the feeding on the tool to be able to remove further volume of the workpiece's material;

- $\mathrm{F}_{\mathrm{p}}$ - the passive force: a result of additional chafing, shearing and deformations during the machining.

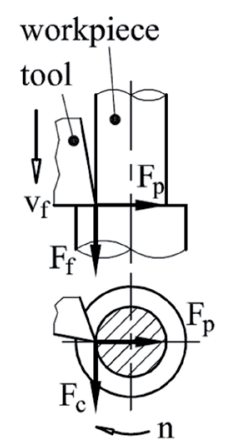

a) Longitudinal turning

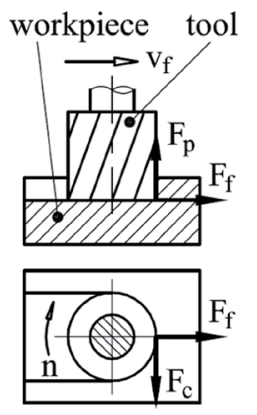

b) Face milling

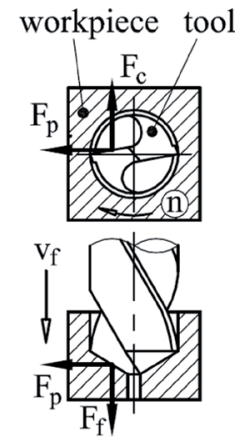

c) Drilling
Fig. 1 Machining force components for typical machining processes 
The orthogonal machining models presume the existence of a shear plane: these models predict bare shearing process between the sections of the crystal-lattice of the material. Such models were created - most notably - by Ernst and Merchant [9] in 1941 and improvements were made by Atkins [3], Lalwani et al. [14] and Williams et al. [24]. An advantage of these models is the fact that the machining forces are predicted using the material properties e.g. shearing resistance. Although the existence of extended shearing volumes instead of exact shearing planes may result the problem of these models. Furthermore, these are unable to handle multi-dimensional machining environment such as shoulder turning, shoulder milling and simple drilling accurately and the undefined shearing angles make the calculation only representative.

On the other hand, empirical expressions are not based on material behaviour models but on direct process parameters e.g. measured forces, temperature, surface properties. An organized, mathematically valid modelling of the machining process has begun with the famous tool life prediction of Frederick Winslow Taylor [20] in 1907. The Taylor-equation established the course of the modelling in the form of exponential functions. [19] This was a major step toward the systematic, predictive production planning. A simplified, general interpretation of an exponential model is described in Eq. (1).

$$
\mathrm{OUT}=\mathrm{LI} \cdot \prod_{\mathrm{i}} \mathrm{IN}_{\mathrm{i}}^{\mathrm{EX}}
$$

where: OUT is the output parameter, LI is a linear coefficient, IN is an input parameter, EX is an exponential coefficient, $\mathrm{i}$ is the identification number of the input parameters. Many of the cutting force models have a similar structure - see Eq. (8).

Such models are being created to describe the machining processes made with definite cutting edge geometry, most notably turning, milling, drilling and broaching. All of these processes are used for a long time and are supported by an extensive amount of technological data. But more precise technologies e.g. micro-machining, new workpiece materials and tools with improved geometry and material properties make some of classical but still traditionally used shaping method's description to be reviewed.

\section{Definition of the specific cutting force}

Basically, the specific cutting force is the cutting force required to remove chip with a section unit:

$$
\begin{gathered}
k_{c}=\frac{F_{c}}{A}, \\
k_{f}=\frac{F_{f}}{A}
\end{gathered}
$$

and

$$
k_{p}=\frac{F_{p}}{A}
$$

where: $\mathrm{k}\left[\mathrm{N} / \mathrm{mm}^{2}\right]$ is the specific cutting force for the particular machining force component, $\mathrm{A}\left[\mathrm{mm}^{2}\right]$ is the chip section, $\mathrm{F}_{\mathrm{c}}$, $F_{f}$ and $F_{p}[N]$ are the main cutting, feeding and passive forces, respectively. This expression serves as start-up for many technological process planning methods e.g. as it is presented by Ko et al. [12], Campatelli et al. [7], Srinivasa et al. [17] and Anand et al. [1]. The actual geometry of the chip section can be defined by additional measuring but for predictive models it is more practical to use a theoretical geometry. This can be calculated by analytical approximation using the basic machining parameters, see Eq. (5-7) and Fig. 2 and Fig. 4:

$$
\begin{gathered}
A(\varphi)=h(\varphi) \cdot b \\
h(\varphi)=f_{z} \cdot \sin \varphi \cdot \sin \kappa
\end{gathered}
$$

and

$$
b=\frac{a_{p}}{\sin \kappa}
$$

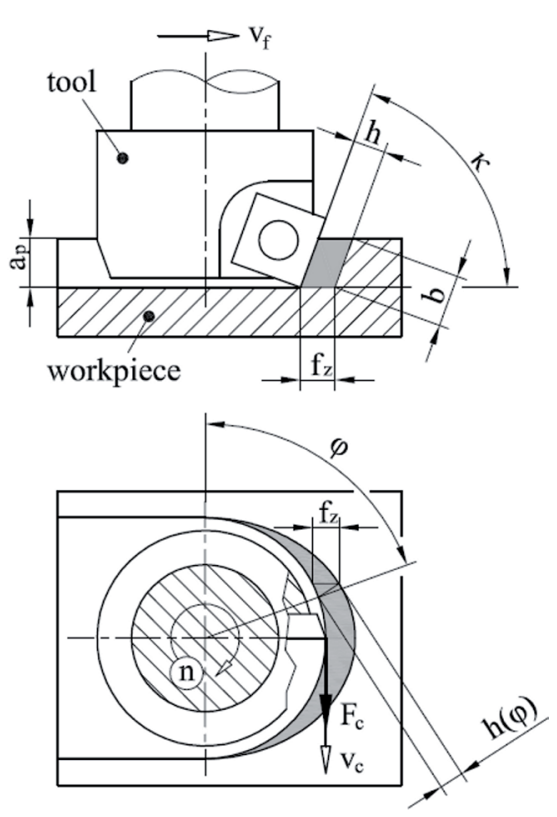

Fig. 2 Basic model of face milling

where: $\mathrm{h}[\mathrm{mm}]$ is the chip-thickness, $\mathrm{b}[\mathrm{mm}]$ is the width of chip, $\mathrm{f}_{\mathrm{z}}[\mathrm{mm}]$ is the feed-rate on the tool's edge, $\varphi$ is the angular position of the edge, $a_{p}[\mathrm{~mm}]$ is the axial depth of cut and $\kappa$ is the axial immersion angle of the main cutting edge. Of course, there are many different, more accurate models first of all for the chip-thickness such as the analytical models of: Kumanchik et al. [13] by creating a coordinate-geometrical model based on the trochoidal trajectory of the cutting edge and Kang et al. [10] by approximating the actual trajectory with Fourier series and the numerical approximations of: Rao et al. [16] by modelling circular and trochoidal tooth trajectory based on relative coordinate-geometrical aspects and Sun et al. [18] by applying finite element method to create discrete sections of the cutting edge and the corresponding chip-thickness. But in the current 
state of this research the expressions of Eq. (6-7) are regarded as adequately accurate models.

Research of the specific cutting force has a long history back to the 1950 es. One of the most prominent analytical models is created by Kienzle and Victor [11] in 1957 where the main cutting force is a function of the theoretical geometry of the chip section and the specific cutting force coefficient. A commonly used variation of the Kienzle-Victor model is presented in Eq. (8):

$$
F_{c}=k_{c 1,1} \cdot h^{x_{F}} \cdot b^{y_{F}} \cdot \prod_{i} K_{i}
$$

where: $k_{c 1,1}$ is the specific cutting force coefficient, $x_{F}$ and $y_{F}$ are the coefficients to take the effect of the chip geometry into account, $\mathrm{K}_{\mathrm{i}}$ is a coefficient of other environmental effects. The $\mathrm{k}_{\mathrm{cl}, 1}$ has a special physical explanation, namely: it is the theoretical (predicted) main cutting force where the section geometry of the removed material is square unit $(\mathrm{h}=\mathrm{b}=1[\mathrm{~mm}])$. This interpretation makes the $\mathrm{k}_{\mathrm{c} 1,1}$ to be a main value of the specific cutting force. Due to the exponential characteristic, the model of Eq. (8) can be easily linearized using a logarithmic coordinate system.

The instantaneous cutting force model includes a similar interpretation of the specific cutting force. It is based on the idea of the finite elements method where the tool's geometry is modelled as a structure of independent segments of the cutting edge - see in Eq. (9). Many studies were made according this theory e.g. by Cheng et al. [7] in 1997, Wan et al. [22] in 2006 and Wan et al. [23] in 2014.

$$
F_{c, i, j}=k_{c} \cdot h_{i, j}(z, \varphi) \cdot b_{i, j}(z)
$$

where: $i$ and $j$ are the identification numbers of the finite cutting edges in the $(\mathrm{x}, \mathrm{y}, \mathrm{z}) 3$-dimensional geometrical model, $\varphi$ is the angular position of the edge. The main difference between these models is the fact that Eq. (8) has a prediction for the machining process in a mean environment such as a mean tool geometry and trajectory. On the other hand, Eq. (9) is valid for a specific section of the ever-changing machining process.

Figure 3 represents a special characteristic of the specific cutting force referred to as size effect. In general, size effect means the phenomena when the ratio of defined parameters can not be kept constant in a process during geometrical scaling. Vollertsen et al. [21] categorize the size effects in manufacturing into three main groups:

a) Size effect of density, e.g. number of unscalable defects in material samples with different (absolute) geometrical scales.

b) Size effect of shape, e.g. correlation between the surface and the volume of an object such as a sphere.

c) Size effect of microstructure, e.g. the discontinuous validity of the Hall-Petch relationship between the grain size and the yield strength of a material due to the unscalable dislocation loops.
The size effect in the specific cutting force is a shape-type size effect where the scaling parameter is the chip-thickness and the related parameter is the specific cutting force. The specific cutting force is a ratio-parameter which has a special correlation to the scaling parameter.

\section{Analytical model for the main cutting force}

In this research, Eq. (8) served as a base for further modelling. As mentioned above, due to its characteristics the specific cutting force model can be linearized thus making linear regression applicable on the measured force values and the linear interpretation makes this model very easy to handle. But few, preceding researchers such as Bali [4] in 1985 mention that the logarithmic specific cutting force can be modelled not only as a single continuous function but also as a multi-sectioned curve based on the same modelling shame with different values for coefficients. These domains are defined by the theoretical chip-thickness as:

- Zone I: $\mathrm{h}>0,1[\mathrm{~mm}]$

- Zone II: $0,01<\mathrm{h} \leq 0,1[\mathrm{~mm}]$

- Zone III: $\mathrm{h} \leq 0,01[\mathrm{~mm}]$ (see Fig. 3)

Measured forces by other researchers such as Ko et al. [12], Campatelli et al. [7], Srinivasa et al. [17], Balogun et al. [5] and Liu et al. [15] also indicate this theory but data are not evaluated from this aspect. Previous researches were made according the multi-sectioned specific cutting force theory [6] and the results hinted the existence of the independent sections - expanded by a new, hypothetical fourth section (Zone IV) which occurs in the technological domain of micro-milling, namely $\mathrm{h}<10[\mu \mathrm{m}]$. The critical chip-thickness values of the section borders are presumably connected to the size of the cutting edge radius. According to the presentations of Anand et al. [1] and Aramcharoen and Mativenga [2] there is a minimum chip-thickness compared to the edge radius which is a requirement to a proper chip removing process. Under the minimum chip-thickness there is increased plastic deformation and this creates different energetic circumstances - as it is predicted by the multi-sectioned specific force model of Fig. 3.

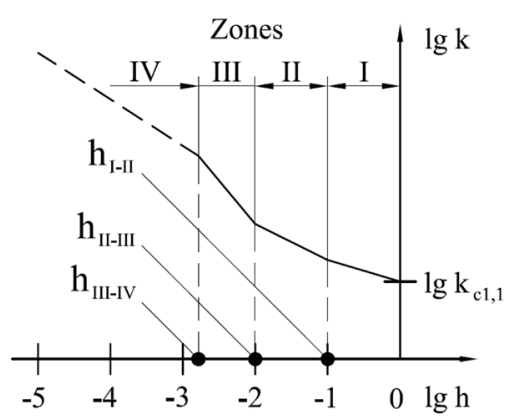

Fig. 3 Linearized, multi-sectioned model of the specific cutting force 
Table 1 Factors and levels of the face milling experiment

\begin{tabular}{|c|c|c|c|c|c|}
\hline No. & Factors & Index & Dimension & Levels & $\begin{array}{c}\text { Total no. of parameter } \\
\text { configurations }\end{array}$ \\
\hline 1 & Cutting speed & $\mathrm{v}_{\mathrm{c}}$ & $\mathrm{m} / \mathrm{min}$ & $75 ; 100 ; 125$ & \multirow{4}{*}{42} \\
\hline 2 & Feed rate on the tool's edge & $\mathrm{f}_{\mathrm{z}}$ & $\mathrm{mm}$ & 0,$01 ; 0,02 ; 0,04$ & \\
\hline 3 & Depth of cut & $a_{p}$ & $\mathrm{~mm}$ & 0,$5 ; 0,75 ; 1$ & \\
\hline 4 & Kinematical direction of cut & DIR & - & conventional; climb & \\
\hline
\end{tabular}

In handbooks there can be found many and well-documented technological information about the value of the coefficients $\mathrm{k}_{\mathrm{cl}, 1}, \mathrm{x}_{\mathrm{F}}$ and $\mathrm{y}_{\mathrm{F}}$ but the effect of a key parameter: the cutting speed is still numerically unexplored or it raises difficulties to find appropriate, namely: statistically accurate and up-to-date information or the data do not characterize the diagram of the specific cutting force as a whole. First and last, an experimental model for the main cutting force is shown in Eq. (10) based on Eq. (8):

$$
F_{c}=k_{c, i, D I R} \cdot h^{x_{F c, i, D I R}} \cdot b^{y_{F c, i, D I R}} \cdot v_{c}^{z_{F c, i, D I R}}
$$

where: $v_{c}[\mathrm{~m} / \mathrm{min}]$ is the cutting speed, $i$ is the identification number of the chip-thickness zones, DIR is an index to identify the kinematical direction of cut: conventional or climb milling (see Fig. 4).

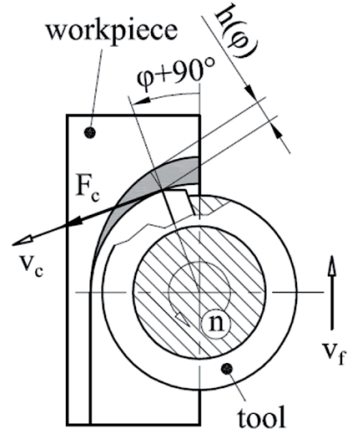

a) Climb milling

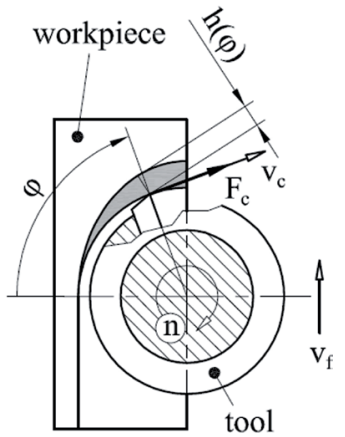

b) Conventional milling
Fig. 4 Kinematics and energetics of climb and conventional milling

\section{The face milling experiment}

The experiments took place in the laboratory of the Department of Manufacturing Science and Engineering, Budapest University of Technology and Economics. Face milling was carried out on a Topper TMW-510T CNC milling-machine and Sumitomo AXMT123504PEERG inserts were used in Sumitomo WEX2016E tool body with nominal diameter of $\mathrm{d}=16[\mathrm{~mm}]$. The milling cutter was used as a single-pointed cutter in order to avoid the superpolation of the cutting forces occurring on the different edges. Force measuring was carried out using a KISTLER 9257B 8-component piezoelectric sensor and a KISTLER 5070A amplifier. The workpiece was S960QL high strength structural steel with nominal chemical deposition of: $\mathrm{C} \%=0,2 ; \mathrm{Si} \%=0,8 ; \mathrm{Mn} \%=1,7 ; \mathrm{Cr} \%=$ 1,$5 ; \mathrm{Ni} \%=2,0 ; \mathrm{Mo} \%=0,7 ; \mathrm{V} \%=1,2\left(\mathrm{HRC}=36, \mathrm{R}_{\mathrm{eH}}=960\right.$
$\left.[\mathrm{MPa}], \mathrm{R}_{\mathrm{m}}=980 \ldots 1150[\mathrm{MPa}]\right)$. Partial factorial experiment was designed to examine correlations between the machining forces and input parameters (factors) shown in Table 1.

\section{Results and Discussions}

Previous industrial observations and researches e.g. by Balogun et al. [5] regard the effect of the width of chip on the main cutting force to be linear. Taking this into consideration, for further calculations it was allowed to be: $\mathrm{y}_{\mathrm{Fc}, \mathrm{i}, \mathrm{DIR}}=1$ and each regression was made for a discrete cutting speed. In this case, a simplified form of Eq. (10) is:

$$
\left.F_{c}\right|_{v_{c}}=k_{c, i, D I R} \cdot h^{x_{F c, i, D I R}} \cdot b
$$

By regrouping Eq. (11) and converting it to the logarithmic system, the expression of the linearized specific cutting force is:

$$
\left.\lg \left(\frac{F_{c}}{h \cdot b}\right)\right|_{v_{c}}=\lg k_{c, i, D I R}+\left(x_{F c, i, D I R}-1\right) \cdot \lg h
$$

Eq. (12) is now the equation of a 2-dimensional linear curve where the specific cutting force is a direct output - see Eq. (2) and Eq. (5). This interpretation is similar of the one presented by Anand et al. [1] for microdrilling where the the effect of the width of chip is considered linear as well and the specific cutting force is a function of the undeformed chip-thickness. Table 2 shows the results according to Eq. (12) and calculated by applying the least square regression method. In Table $2, \mathrm{~h}_{\text {II-III }}$ and $\mathrm{h}_{\text {III-IV }}$ indicates - according to Fig. 3 - the nominal chip-thicknesses where the specific cutting force has a change of characteristic. Table 2 also contains the coefficients of the single linear model for Zone II-IV, it is marked as "Unified".

Transforming Eq. (10) the way it was carried out in Eq. (12) and still regarding $\mathrm{y}_{\mathrm{Fc}, \mathrm{i}, \mathrm{DIR}}=1$, Eq. (13) presents the specific cutting force as a function of chip section and cutting speed thus creating a 3-dimensional model:

$$
\lg \left(\frac{F_{c}}{h \cdot b}\right)=\lg k_{c, i, D I R}+\left(x_{F c, i, D I R}-1\right) \cdot \lg h+z_{F c, i, D I R} \cdot v_{c}
$$

Table 3 contains the calculated coefficients for Eq. (13) and the collective coefficients for Zones II-IV, marked as "Unified".

Studying Tables 2-3, it is remarkable that the effect of the chip-thickness $\left(\mathrm{x}_{\mathrm{Fc}, \mathrm{i}, \mathrm{DIR}}\right)$ shows little difference between the multi-sectioned and the one-sectioned models. On the other hand, the specific cutting force coefficients $\left(\mathrm{k}_{\mathrm{c}, \mathrm{i}, \mathrm{DIR}}\right)$ have relative 
Table 2 Coefficients of the 2-dimensional simplified model

\begin{tabular}{|c|c|c|c|c|c|c|}
\hline $\mathbf{v}_{\mathrm{c}}[\mathbf{m} / \mathbf{m i n}]$ & DIR & $\mathbf{i}$ & $\mathbf{x}_{\mathrm{Fc}, \mathrm{i}, \mathrm{DIR}}[-]$ & $\mathbf{k}_{\mathrm{c}, \mathrm{i}, \mathrm{DIR}}\left[\mathbf{N} / \mathbf{m m}^{2}\right]$ & $\mathbf{h}_{\mathrm{III-IV}}[\mathrm{mm}]$ & $\mathbf{h}_{\mathrm{II}-\mathrm{III}}[\mathrm{mm}]$ \\
\hline \multirow{8}{*}{75} & \multirow{4}{*}{ Climb } & IV & 0,453 & 1310 & \multirow{3}{*}{0,0045} & \multirow{3}{*}{0,0095} \\
\hline & & III & 0,082 & 176 & & \\
\hline & & II & 0,281 & 446 & & \\
\hline & & Unified & 0,275 & 442 & - & - \\
\hline & \multirow{4}{*}{ Conventional } & IV & 0,153 & 346 & \multirow{3}{*}{0,0014} & \multirow{3}{*}{0,0162} \\
\hline & & III & 0,059 & 187 & & \\
\hline & & II & 0,507 & 1185 & & \\
\hline & & Unified & 0,128 & 274 & - & - \\
\hline \multirow{8}{*}{100} & \multirow{4}{*}{ Climb } & IV & 0,249 & 431 & \multirow{3}{*}{0,0027} & \multirow{3}{*}{0,0091} \\
\hline & & III & 0,164 & 261 & & \\
\hline & & II & 0,553 & 1629 & & \\
\hline & & Unified & 0,313 & 607 & - & - \\
\hline & \multirow{4}{*}{ Conventional } & IV & 0,184 & 429 & \multirow{3}{*}{0,0013} & \multirow{3}{*}{0,0028} \\
\hline & & III & 0,030 & 155 & & \\
\hline & & II & 0,221 & 474 & & \\
\hline & & Unified & 0,173 & 367 & - & - \\
\hline \multirow{8}{*}{125} & \multirow{4}{*}{ Climb } & IV & 0,130 & 182 & \multirow{3}{*}{0,00006} & \multirow{3}{*}{0,0125} \\
\hline & & III & 0,333 & 809 & & \\
\hline & & II & 0,397 & 1072 & & \\
\hline & & Unified & 0,348 & 860 & - & - \\
\hline & \multirow{4}{*}{ Conventional } & IV & 0,321 & 1105 & \multirow{3}{*}{0,0017} & \multirow{3}{*}{0,0030} \\
\hline & & III & 0,224 & 597 & & \\
\hline & & II & 0,121 & 328 & & \\
\hline & & Unified & 0,181 & 449 & - & - \\
\hline
\end{tabular}

Table 3 Coefficients of the 3-dimensional specific cutting force model

\begin{tabular}{|c|c|c|c|c|c|c|}
\hline \multirow{2}{*}{ DIR } & \multirow{2}{*}{ Coefficients } & \multicolumn{3}{|c|}{ Zone number (i) } & \multicolumn{2}{|c|}{ Unified } \\
\hline & & IV & III & II & Based on Eq. (13) & Based on Eq. (12) \\
\hline \multirow{3}{*}{ Climb } & $\mathrm{k}_{\mathrm{c}, \mathrm{i}, \mathrm{DIR}}$ & 45 & 39 & 17 & 19 & 636 \\
\hline & $\mathrm{X}_{\mathrm{Fc}, \mathrm{i}, \mathrm{DIR}}$ & 0,335 & 0,217 & 0,410 & 0,336 & 0,312 \\
\hline & $\mathrm{Z}_{\mathrm{Fc}, \mathrm{i}, \mathrm{DIR}}$ & 0,608 & 0,493 & 0,869 & 0,784 & - \\
\hline \multirow{3}{*}{ Conventional } & $\mathrm{k}_{\mathrm{c}, \mathrm{i}, \mathrm{DIR}}$ & 199 & 32 & 135 & 91 & 363 \\
\hline & $\mathrm{X}_{\mathrm{Fc}, \mathrm{i}, \mathrm{DIR}}$ & 0,173 & 0,134 & 0,254 & 0,177 & 0,161 \\
\hline & $\mathrm{z}_{\mathrm{Fc}, \mathrm{i} \text { DIR }}$ & 0,149 & 0,491 & 0,291 & 0,315 & - \\
\hline
\end{tabular}

great differences. This leads to the conclusion that the effect of the cutting speed is considerable as it is expected based on industrial experience and previous researches. Remarkable differences can be noticed between the conventional and climb milling in Zones II and IV. Although, the coefficients of cutting speed and specific cutting force in Zone III show great resemblance in between the two kinematical versions of face milling. The critical chip-thicknesses: $h_{\text {II-III }}$ and $h_{\text {III-IV }}$ have mean values around $10,4[\mu \mathrm{m}]$ and $2,6[\mu \mathrm{m}]$, respectively. The mean value of $\mathrm{h}_{\text {II-III }}=10,4[\mu \mathrm{m}]$ shows great resemblance to previous models as presented in Fig. 3. These results can be regarded as an indirect mapping of the shearing and deformational processes in the material of workpiece during machining. Unfortunately, these results are still representative due to the high and unexplored deviation of experimental results but they give a good approximation about the expectable outcomes for future researches. Fig. 5-6 show visual presentations of the analytical results collected in Tables 2-3.

The results conformed the expectations about the effects of the input parameters and serve as a start-up for a unified, complex and mathematically grounded cutting force modelling method. Although these results are still representative, they foreshadow the possibility of improvement and extension of some classical models of the specific cutting force. In order to do so, validation of the extended multi-sectioned specific cutting force model is highly needed by improved measuring setup and by applying 

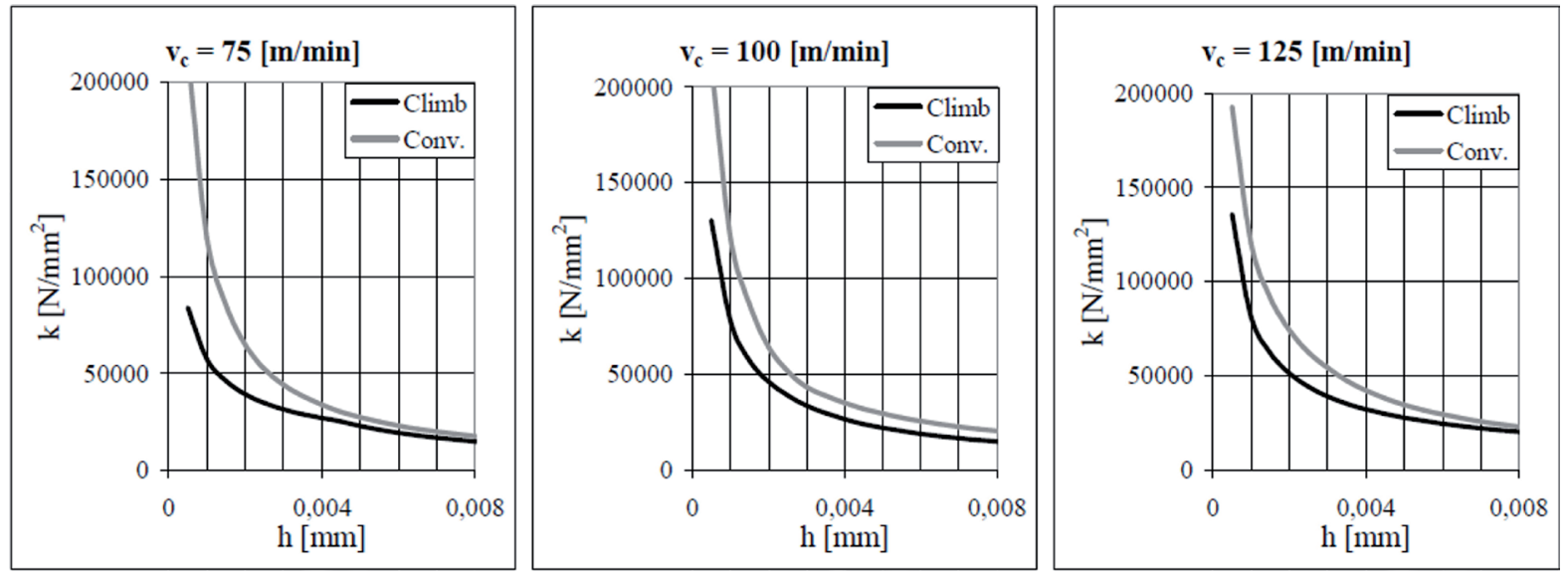

Fig. 5 Multi-sectioned specific cutting force model for discrete cutting speeds
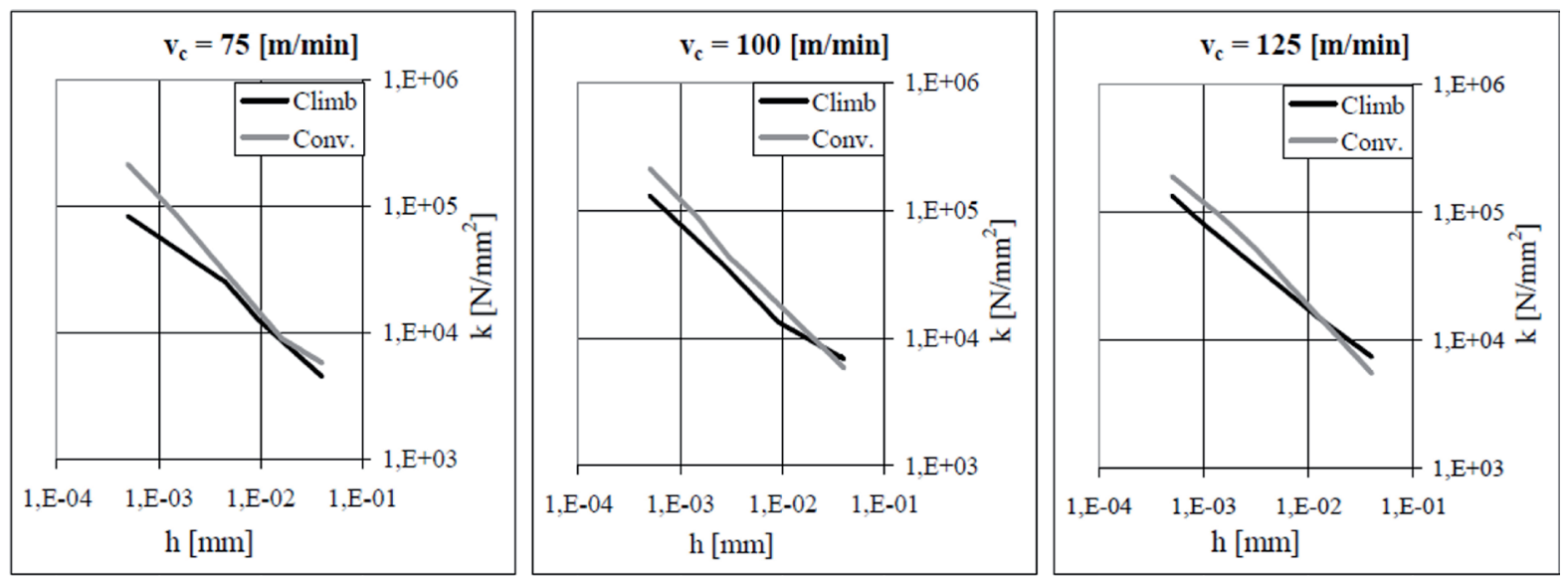

Fig. 6 Multi-sectioned specific cutting force model in the logarithmic system

other technologies such as turning and drilling. Possible courses of improvement are the interpretation of the specific cutting force as a mathematical function of cutting speed and analyzing the effect of the cutting speed on the section-borders of the multisectioned specific cutting force model. The method of the face milling experiments (including data evaluation) makes it possible to extend the experiments on further type of steels. Deformations and fracture mechanisms of steel workpieces consist the same sub-mechanisms only with different extensions. This creates the opportunity to apply the extended multi-sectioned specific force model to other materials as well. This can lead to the creation of an advanced, comparative data base of machinability and predictive technological models.

\section{Conclusions}

Face milling tests provide process data from the minimum (theoretically zero) chip-section to a maximum value defined by the feed rate. This makes the tests to be suitable to explore the specific machining forces where the only discretizing factor is the measuring frequency.

The specific cutting force can be modelled as a multisectioned exponential function. Previous researches already proved the existence of the multi-sectioned nature including the exact values of critical chip-thicknesses where the model has significant change of characteristic. A new critical chipthickness was identified at $\mathrm{h}=2 \ldots 3[\mu \mathrm{m}]$.

The cutting speed has a degressive effect on the specific cutting force. The intensity of this effect differs between the two kinematical types of face milling: according to Eq. (13) the exponential coefficient of the cutting speed is around $0.5 \ldots 0.8$ in climb milling and $0.15 \ldots 0.5$ in conventional milling. The cutting speed has less effect on the main cutting force in conventional milling regarding the applied range of parameters.

\section{Acknowledgement}

The work reported in this paper connected to the project „Talent care and cultivation in the scientific workshops of BME" project. That project is supported by the grant TÁMOP4.2.2.B-10/1--2010-0009. The authors would like to acknowledge support provided by CEEPUS III HR 0108 project. The authors would also like to render thanks to Sumitomo Electric Hardmetal Ltd. for providing the milling tool and inserts.

\section{References}

[1] Anand, R. S., Patra, K., Steiner, M. "Size effects in micro drilling of carbon fiber reinforced plastic composite." Production Engineering Research and Development. 8 (3). pp. 301-307. 2014. DOI: $10.1007 / \mathrm{s} 11740-014-0526-2$ 
[2] Aramcharoen, A., Mativenga, P. T. "Size effect and tool geometry in micromilling of tool steel." Precision Engineering. 33 (4). pp. 402-407. 2009. DOI: 10.1016/j.precisioneng.2008.11.002

[3] Atkins, A. G. "Modelling Metal Cutting Using Modern Ductile Fracture Mechanics: Quantitative Explanations for Some Longstanding Problems." International Journal of Mechanical Sciences. 45 (2). pp. 373 396. 2003. DOI: 10.1016/S0020-7403(03)00040-7

[4] Bali, J. "Forgácsolás." (Machining.) Budapest: Tankönyvkiadó. 1985. (In Hungarian)

[5] Balogun, V. A., Mativenga, P. T. "Impact of Un-deformed Chip Thickness on Specific Energy in Mechanical Machining Processes." Journal of Cleaner Production. 69. pp. 260-268. 2014.

DOI: 10.1016/j.jclepro.2014.01.036

[6] Biró, I., Szalay, T., Markos, S. "Machinability of S960QL High Strength Structural Steel: Energetic Description of Cutting at Small Chip-thickness in Face Milling." In: Z. Car, J. Kudláček, T. Szalay (eds). International Conference on Innovative Technologies, IN-TECH. 2013.

[7] Campatelli, G., Scippa, A. "Prediction of Milling Cutting Force Coefficients for Aluminum 6082-T4." Procedia CIRP. 1. pp. 563-568. 2012. DOI: 10.1016/j.procir.2012.04.100

[8] Cheng, P. J., Tsay, J. T., Lin, S. C. "A Study on Instantaneous Cutting Force Coefficients in Face Milling." International Journal of Machine Tools and Manufacture. 37 (10). pp. 1393-1408. 1997. DOI: 10.1016/S0890-6955(97)00004-7

[9] Ernst, H., Merchant, M. E. "Chip Formation, Friction and High Quality Machined Surfaces." Transactions of American Society for Metals. 29. pp. 299-378. 1941.

[10] Kang, Y. H., Zheng, C. M. "Mathematical Modelling of Chip Thickness in Micro-end- Milling: A Fourier Modelling." Applied Mathematical Modelling. 37 (6). pp. 4208-4223. 2013. DOI: 10.1016/j.apm.2012.09.011

[11] Kienzle, O., Victor, H. "Spezifische Schnittkräfte bei der Metallbearbeitung." Werkstattstechnik und Maschinenbau. 47. pp. 22-25. 1957.

[12] Ko, J. H., Yun, W.-S., Cho, D.-W., Ehmann, K. F. "Development of a Virtual Machining System, Part 1: Approximation of the Size Effect for Cutting Force Prediction." International Journal of Machine Tools and Manufacture. 42 (15). pp. 1595-1605. 2002.

DOI: 10.1016/S0890-6955(02)00137-2

[13] Kumanchik, L. M., Schmitz, T. L. "Improved Analytical Chip Thickness Model for Milling." Precision Engineering. 31 (3). pp. 317-324. 2007. DOI: 10.1016/j.precisioneng.2006.12.001

[14] Lalwani, D. I., Mehta, N. K., Jain, P. K. "Extension of Oxley's Predictive Machining Theory for Johnson and Cook Flow Stress Model." Journal of Materials Processing Technology. 209 (12-13). pp. 5305-5312. 2009. DOI: 10.1016/j.jmatprotec.2009.03.020
[15] Liu, K., Melkote, S. N. "Material Strengthening Mechanisms and Their Contribution to Size Effect in Micro-Cutting." Journal of Manufacturing Science and Engineering. 128 (3). pp. 730-738. 2005. DOI: 10.1115/1.2193548

[16] Rao, V. S., Rao, P. V. M. "Modelling of Tooth Trajectory and Process Geometry in Peripheral Milling of Curved Surfaces." International Journal of Machine Tools and Manufacture. 45 (6). pp. 617-630. 2005. DOI: 10.1016/j.ijmachtools.2004.10.004

[17] Srinivasa, Y. V., Shunmugam, M. S. "Mechanistic Model for Prediction of Cutting Forces in Micro End-milling and Experimental Comparison." International Journal of Machine Tools and Manufacture. 67. pp. 18-27. 2013. DOI: 10.1016/j.ijmachtools.2012.12.004

[18] Sun, Y., Guo, Q. "Numerical Simulation and Prediction of Cutting Forces in Five-axis Milling Processes with Cutter Run-out." International Journal of Machine Tools and Manufacture. 51 (10-11). pp. 806-815. 2011. DOI: 10.1016/j.ijmachtools.2011.07.003

[19] Szalay, T. "Modelling in Metal Cutting Theory." In: B. Barišić (ed) Concurrent Product and Technology Development. Kastav, Fintrade and Tours. 2009.

[20] Taylor, F. W. "On the Art of Cutting Metals." New York, The American Society of Mechanical Engineers. 1907.

[21] Vollertsen, F., Biermann, D., Hansen, H. N., Jawahir, I. S., Kuzman, K. "Size effects in manufacturing of metallic components." CIRP Annuals Manufacturing Technology. 58 (2). pp. 566-587. 2009.

DOI: 10.1016/j.cirp.2009.09.002

[22] Wan, M., Zhang, W. H., Qin, G. H., Tan, G. "Efficient Calibration of Instantaneous Cutting Force Coefficients and Runout Parameters for General End Mills." International Journal of Machine Tools and Manufacture. 47 (11). pp. 1767-1776. 2007. DOI: 10.1016/j.ijmachtools.2006.06.012

[23] Wan, M., Pan, W.-J., Zhang, W.-H., Ma, Y.-C., Yang, Y. "A Unified Instantaneous Cutting Force Model for Flat End Mills with Variable Geometries." Journal of Materials Processing Technology. 214 (3). pp. 641-650. 2014. DOI: 10.1016/j.jmatprotec.2013.10.016

[24] Williams, J. G., Patel, Y., Blackman, B. R. K. "A Fracture Mechanics Analysis of Cutting and Machining." Engineering Fracture Mechanics. 77 (2). pp. 293-308. 2010. DOI: 10.1016/j.engfracmech.2009.06.011 